\title{
LA REINVENCIÓN DE UNA VOCACIÓN REGIONAL Agroexportadora. El CORREDOr COSTERo DE ChiApas ${ }^{1}$
}

\author{
Héctor B. Fletes Ocón
}

\begin{abstract}
Resumen: Desde una perspectiva antropológica, en este trabajo se analizan procesos de producción, representaciones sociales y discursos que en diferentes momentos han otorgado una cualidad agroexportadora al Corredor Costero de Chiapas, en particular al Soconusco. Se sostiene que además de elementos materiales, la región se construye por un conjunto de representaciones simbólicas que reafirman la identidad y el poder regional. La reinvención de una vocación regional agroexportadora manifiesta la capacidad de los actores sociales locales para responder a diferentes situaciones problemáticas. Pero también expresa la participación desigual de los grupos sociales en la reproducción de esos símbolos, y de la exclusión en las cadenas agroindustriales.
\end{abstract}

Palabras clave: Región, antropología, simbólico, Corredor Costero, Soconusco, Chiapas, agroexportación, cadenas agroindustriales, mango.

Enviado a dictamen: 04 de agosto de 2009

Aprobación: 12 de septiembre de 2009

Revisiones: 2

Héctor B. Fletes Ocón, doctor en Ciencias Sociales con especialidad en Antropología Social por el CIESAS Occidente, profesor de la licenciatura en Gestión y Autodesarrollo Indígena, IEI, Universidad Autónoma de Chiapas, San Cristóbal de Las Casas, Chiapas; México, temas de especialización: Globalización Agroalimentaria; Procesos de Cambio Regional; Estado y Sociedad, correo electrónico: hctrfo@gmail.com.
Abstract: Based in anthropological perspective, this work analyses production processes, social representations and discourses that in different moments have given to the Chiapas Corredor Costero, particularly to Soconusco, a quality of export-oriented agriculture. It is argued that besides of material elements, the region is constructed by a set of symbolic representations that assert the regional identity and power. The reinvention of an "exportoriented agriculture" regional vocation manifests the capacity of social local actors to respond to different problematic situations. But it also expresses the social groups' unequal participation in reproducing those symbols and of the exclusion in agrifood chains.

Key Words: region, anthropology, symbolic, Corredor Costero, Soconusco, Chiapas, export-oriented agriculture, agrifood chains, mango.

\section{Introducción}

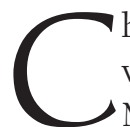
hiapas es uno de los estados con los más elevados niveles de marginación y pobreza en México (PNUD, 2005), situación que parece empeorar en las últimas décadas (Méndez et. al., 2007). Su población está dispersa en una numerosa cantidad de localidades rurales. De acuerdo con el Conteo de Población del INEGI (2006a), en el año 2005, tres ciuda- 
des (Tuxtla Gutiérrez, Tapachula y San Cristóbal de Las Casas) concentraron 19\% de la población, mientras que 52\% de ella vivía en 19,237 localidades menores a 2,500 habitantes.

Este patrón de asentamiento es de carácter histórico, y se relaciona con varios procesos, entre los que pueden mencionarse los siguientes: las dinámicas de poblamiento del sureste mexicano ligadas con políticas agrarias, de productividad agrícola y respuesta a demandas sociales; continua expansión de superficies para uso agropecuario en condiciones de gran polarización (minifundios a la par de grandes explotaciones); expulsiones de población por motivos religiosos o familiares, disputas entre poseedores de tierra y jornaleros, y la creación de nuevos poblados; desplazamientos por el movimiento zapatista en 1994; y, finalmente, tal asentamiento disperso se asocia con el fraccionamiento de las tierras por el crecimiento poblacional y traspasos dentro de las familias (Del Rey, 1998; Reyes, 1992; Pérez, 1998).

Como en el resto del estado de Chiapas, en el Corredor Costero que abarca las regiones "Costa" y "Soconusco", 2 se han presentado una gran dispersión de la población y transformaciones sociales radicales en las dos últimas décadas. Hay una "crisis" y diversificación de la agricultura, así como una migración rural y urbana creciente hacia los Estados Unidos. A pesar de ello, el dinamismo agrícola de esta región no parece agotarse. Las prácticas de los agricultores, las relaciones entre ellos y los agentes del Estado, y el discurso sobre el territorio por académicos y otros actores (visitantes, profesionistas y empresarios), recrean constantemente su potencial agrícola exportador. En ese sentido, el presente trabajo sostiene que, además de los procesos materiales y productivos, elementos simbólicos integrados a la idea y prácticas de una "vocación agroexportadora", contribuyen en la construcción de la región y en sus procesos identitarios y de poder. En el siguiente apartado, se revisa el tratamiento que académicos de distintas disciplinas han dado al concepto de región en México, y se ubica el presente trabajo en esa discusión, resaltando que la perspectiva distintiva del mismo se basa en un análisis inductivo de la región, estudiando su heterogeneidad social y cultural, así como los procesos históricos, más que definiéndola a partir de sus indicadores plasmados en estadísticas oficiales. Las regiones no se pueden tomar como algo dado, o como espacios homogéneos y estáticos, puesto que están en continua configuración e imaginación. Asimismo, los actores se identifican de manera distinta y cambiante con las regiones, otorgándoles una configuración territorial sumamente dinámica. Se analizan, también, los procesos económicos, sociales y políticos que han otorgado a la región del Corredor Costero ciertas características particulares, así como su construcción a partir de elementos discursivos y simbólicos. Posteriormente, se estudian los efectos que han tenido en la región las políticas de corte neoliberal de las últimas décadas, las respuestas diferenciadas de los grupos sociales a esta dinámica y los procesos de reproducción del discurso regional agroexportador ${ }^{3}$. Para finalizar, se presentan algunas reflexiones.

\section{Región y territorio en México}

El concepto región tiene significados variados entre los académicos. Los economistas y algunos sociólogos se adhieren a las perspectivas de la "Ciencia Regional", que abarca los análisis de polos de desarrollo, relaciones y flujos entre regiones, difusión del crecimiento o relaciones insumo-producto. Recientemente, estudian los procesos de convergencia económica (Fuentes, et. al., 2003), los sistemas productivos y distritos industriales (Saraví, 2003 - desde una perspectiva más antropológica-). Otros académicos en esta línea destacan la importancia del tiempo y espacio como dimensiones clave de las actividades económicas en la región, así como su complejidad multidimensional. ${ }^{4}$ Los lugares son definidos social e históricamente; el espacio es una producción social, relacionada con el entorno físico, 
y representado de manera "científica" o "imaginaria" (Asuad, 2007: 139; Rivera, 2007: 115, 118).

Por su parte, los antropólogos sociales se centran en los procesos de apropiación o representación del espacio, en las dinámicas regionales construidas por actores sociales diversos como los empresarios, caciques, agricultores y grupos de poder (De la Peña, 1986; Estrada y Labazeé, 2007). Se enfocan en la diversidad sociocultural y los procesos de adaptación-transformación ecológica en áreas determinadas. ${ }^{5}$ Así, De la Peña (1999: 39) resume en cuatro los tipos de estudio regional en México: el primero se centra en los sistemas productivos regionales; el segundo, en los mercados regionales de productos y de trabajo; el tercero, se refiere a los sistemas de dominación regional; y el cuarto a los patrones regionales de cultura.

Roberts (1992: 227) señala que en México han predominado dos posiciones al estudiar la región: una es la costumbre de tratar las regiones como objetos de estudio en sí mismos, en los cuales la intención es mostrar qué es lo particular de una región dada. Aquí se pregunta acerca de la identidad (en términos políticos, sociales y culturales) de la región, su grado de integración, sus aspectos históricos, actividades económicas, ecológicas, y patrones de comunicación. La segunda tradición ve la importancia de la región en su contribución a la configuración específica de la nación. Roberts propone en esta discusión que las regiones cambian tanto en términos de sus grupos componentes como en la intensidad de identificar a estos grupos con el espacio, en la medida que los actores sociales compiten entre ellos para imponer su definición de qué es una región y a qué intereses sirve:

Las regiones son, entonces, proyectos que surgen de las negociaciones de los varios actores locales: comerciantes, propietarios de tierra, campesinos, militares y otros caciques. La región puede significar cosas diferentes a estos actores, y en el tiempo puede haber cambios tanto en las fronteras identificadas con una región como en la naturaleza de los actores involucrados en construir una identidad regional. Pero la negociación, y la cultura simbólica y conjuntos de relaciones sociales que tanto hacen la negociación posible como son formados por ella, implican el forjamiento de una identidad regional y su persistencia (Roberts, 1992: 228,229).

Vemos entre estas posiciones no sólo una distinción por intereses de investigación. Subyace una distinción epistemológica entre una posición hipotética-deductiva y otra de carácter inductiva abierta a la multiplicidad de voces y procesos de construcción de los territorios, posición en la que se inserta este trabajo.

Ahora bien, en los estudios de región en México ha predominado la perspectiva económica. ${ }^{6}$ Es decir, el estudio de los procesos sociales localizados espacialmente, se ha basado en la noción de región como espacio socio-económico, más que en la de territorio como espacio valorizado de distintas maneras y en continua construcción. ${ }^{7}$ de igual manera, las agencias del Estado en México han aplicado en sus programas una noción económica-geográfica de región. Durante mediados del siglo XX, con el término región se pensaba en un espacio vacío para la aplicación de políticas, las cuales se concretaron en la instalación de infraestructura para el "desarrollo regional". Como ejemplo se encuentran los planes de desarrollo a través de Comisiones de Cuenca Hidrográfica, que condujeron a la construcción de presas hidroeléctricas, siendo Chiapas uno de los estados "beneficiados". La base de esta estrategia fue la experiencia de la Tenesse Valley Authority en los Estados Unidos (Viqueira, 2001). Los responsables de esta política pensaban que las Cuencas eran el área adecuada de intervención, ya que que las dinámicas de tales regiones impulsarían procesos productivos y "encadenamientos" económicos y sociales que conducirían al desarrollo.

Recientemente, como resultado de una (auto) crítica sobre las experiencias fallidas de desarrollo regional, y 
además influidos por las experiencias europeas sobre desarrollo local, algunos académicos que habían estado apegados al concepto de región vienen centrándose en la noción de territorio. De manera similar, los actores políticos y sus asesores han entendido tal concepto como un "espacio de potencialidades locales" o de "recursos escondidos" para el desarrollo, y se le ha aceptado en los círculos gubernamentales como el espacio apropiado de intervención. ${ }^{8}$

De acuerdo con estas precisiones conceptuales, se puede señalar que los estudios sobre algunas problemáticas del Corredor Costero de Chiapas han prestado poca atención a la construcción del espacio como una serie de negociaciones entre actores de muy diversa índole, como son empresarios, agricultores, profesionistas, académicos y agentes del Estado, que intentan configurarlo y representarlo de un modo conveniente a sus intereses y proyectos. Desde esta perspectiva, y con base en los trabajos de Roberts (1992), Pujadas (2003), Anderson (1996) y Nay (1998), ${ }^{9}$ se usará aquí el término región a partir de los diferentes territorios, imaginaciones, discursos, representaciones y proyectos de grupos de actores sociales. La presencia de grupos diversos en la región arroja un escenario dinámico y multicultural. Estos grupos "están implicados en una compleja dialéctica por la hegemonía cultural, económica y política..." (Pujadas, 2003: 455), tal, que el mismo proceso de instauración de símbolos identitarios [regionales] "es objeto de control y dirección por parte de una elite social de acuerdo con su ideario y con su proyecto de acción política" (Pujadas, 2003: 481).

\section{El Corredor Costero de Chiapas: una construcción social}

Se propone centrarse en el Corredor Costero de Chiapas como una estrategia para aprehender las dinámicas históricas entre la población, recursos y sistemas productivos entre dos áreas que son conocidas en la literatura y en los organismos gubernamentales (INEGI) como dos regiones: la "Costa" y el "Soconusco" (Figura l). Aunque sus vínculos son históricos, un aspecto reciente de esta interdependencia y complementariedad entre ambos espacios puede mostrarse en los procesos socioculturales de las cadenas agroindustriales de mango, los cuales se discuten al final del trabajo.

La definición y caracterización de este espacio ha sido un asunto problemático. Para Aubry (2006: 93), históricamente el Soconusco incluye todos los municipios del Corredor Costero: "en un sentido amplio e histórico, el Soconusco es un angosto corredor de $260 \mathrm{kms}$. entre el Océano Pacífico y la Sierra Madre de Chiapas". Fue ulteriormente dividido, desde el punto de vista administrativo, en tres regiones económicas identificadas por sus notorias diferencias climáticas:

$$
\begin{aligned}
& \text {... Istmo-Costa - los tres primeros municipios cuando } \\
& \text { se viene desde la frontera con Oaxaca-, Soconusco- } \\
& \text { un hormigueo de municipios entre Mapastepec y la } \\
& \text { frontera de Guatemala-, y Sierra - otros municipios } \\
& \text { montañosos pegados a la misma frontera-, pero que, } \\
& \text { a diferencia de los demás, no desaguan hacia el Pací- } \\
& \text { fico, sino hacia los valles centrales (Aubry, 2006:93). }
\end{aligned}
$$

En su período prehispánico, el Soconusco consta de toda la banda costera: el pie de monte de la Sierra Madre de Chiapas que, dominado por despeñaderos, corre del Istmo de Tehuantepec (Oaxaca) a la frontera de Guatemala (Aubry, 2006: 95). Desde ese tiempo, este territorio fue codiciado por ser un corredor estratégico de comunicación política y comercial de Mesoamérica, para unir su parte occidental (llamada Nueva España por los españoles) y su parte oriental (la Provincia de los Confines del Conquistador, hoy Centroamérica), separadas por la barrera geológica del Istmo de Tehuantepec (Aubry, 2006: 95).

Durante la Colonia, tal espacio conservó una relativa autonomía como Gobernación, que comprendía desde la jurisdicción de Tonalá al distrito de Mariscal, hoy Motozintla (Pohlenz, 1985: 58). A partir de 1790 se 
suprimen las Alcaldías Mayores de Ciudad Real (hoy San Cristóbal de Las Casas) y Tuxtla, y la gobernación de Soconusco, creándose una sola Provincia: la Intendencia de Chiapas y Soconusco; éste último se integra entonces con los Partidos de Tapachula y Tonalá, que abarcaban los pueblos de Tapachula, Tonalá, Tuxtla de Soconusco, Metapa, Huehuetán, Mazatán, Tuzantán, San Felipe Tizapa, Escuintla, Acacoyagua, Acapetahua, Motozintla, Mazapa, Siltepec, Pishishiapa, Mapashtepeque y Quetzalapa:

La región del Soconusco comprende la zona costera de Chiapas que se prolonga hasta el río Tilapa en la actual República de Guatemala. Estos límites la definieron hasta su integración a México en 1842 (Pohlenz, 1985: 58)"

En 1846, con el objeto de precisar los límites territoriales de la República Mexicana, el gobernador Ángel Albino Corzo presenta al Congreso una carta general del estado, en donde en la zona costera se establecen dos departamentos. El de Tonalá abarcaba desde la frontera con Oaxaca hasta Mapastepec; el de Soconusco se formaba con el resto de los municipios que la integraban hasta antes de esta división (Ibíd.: 59).

En respuesta a esta construcción problemática de región, desde el punto de vista geográfico Bassols y otros (1974) han conciderado que el municipio de Mapastepec pertenecía a la región "Costa". Para ello se basaron en la presencia de vientos secos abundantes desde Arriaga hasta ese municipio, así como en diferencias hidrológicas con el Soconusco. ${ }^{12}$ También la actividad productiva ha sido un elemento en el que académicos encuentran diferencias entre el Soconusco y la Costa. Según Toledo, en todo el Corredor Costero de Chiapas predominan tres actividades primarias: la ganadería, en dos terceras partes de la planicie, desde los límites con Oaxaca hasta Mapastepec, en la región conocida como "la Costa"; la agricultura, en la tercera parte hacia el sureste hasta los límites con Guatemala, en la región del "Soconusco"; y la pesca, que se practica a lo largo de sus amplias y productivas lagunas costeras (Toledo, 1994a: 57, 58). En particular, en el Soconusco predomina la agricultura de plantación. Es la región del trópico húmedo de México "donde la agricultura basada en monocultivos comerciales ha alcanzado uno de sus más altos niveles tecnológicos y de organización capitalista de la producción. [Es] Altamente especializada en productos de exportación, como el café y el plátano..." (Toledo, 1994a: 59, 61).

Sin embargo, el Corredor Costero forma una sola "Región Hidrológica", la 23, denominada "Costa de Chiapas" (Toledo, 1994b: 27, 28). Comprende parte de la costa oaxaqueña y se prolonga al sureste hasta los límites con Guatemala. La integran cuatro cuencas: Suchiate, Huixtla, Pijijiapan y Ocuilapan-Mar Muerto. ${ }^{13}$ En ese sentido el Corredor Costero comparte una situación natural relativamente homogénea en su interior, sobre todo si se le compara con el resto del estado de Chiapas. Así lo manifiestan Bassols y sus colaboradores, al afirmar que ambas subregiones son parte de una misma región socioeconómica de Chiapas, y tienen una relación mutua. El Soconusco recibe de la Costa diversos productos ganaderos y agrícolas, así como algunos pesqueros y de la industria de la construcción, enviándole a su vez ciertas cantidades de artículos de la industria ligera y de alimentos (Bassols, et. al. 1974: 34, 35). Existen entonces inconsistencias en la definición de esta región debido en parte al dinamismo de los procesos (muchos de ellos contiendas políticas) en los que se centran sus estudiosos para caracterizarla, así como en sus visiones particulares. Como dice De la Peña (1999: 39): "lejos de concebirse como estáticas, las regiones se constituyen en objetos cambiantes, cuya naturaleza se define por el problema cuyas dimensiones espaciales quieren investigarse".

Debemos observar que las anteriores representaciones de la región no se circunscriben al ámbito académico. Ellas son, también, parte de las relaciones cotidianas y discursos de la población local, ámbito en el 
que tales representaciones se utilizan como símbolos de diferenciación social. En ocasiones, habitantes de localidades del "Soconusco" utilizan en diálogos cotidianos frases como "aquí en la Costa...", cuando se refieren a alguna situación respecto al resto del estado; es decir, no establecen una diferencia regional Soconusco-Costa. Pero también se dice en estos diálogos, en informes de gobierno y notas periodísticas que el Soconusco es "más productivo que la Costa", marcando una diferencia territorial. Así pues, los discursos de los actores locales muestran una diversidad en la apropiación del espacio. Esta polifonía manifiesta la diversidad de las experiencias socioculturales de los actores, y la construcción de la región desde las propias representaciones, discursos y pugnas entre ellos. En ese sentido, la diferenciación regional representa una diferenciación social, una forma en que cultura simbólica juega un papel, como veremos, en el control de los términos de negociación sobre recursos diversos, así como de los procesos de transformación regional.

\section{El diseño de una región agroexportadora y capitalista.}

Un conjunto de procesos de producción agrícola para exportación y la situación geográfica de frontera internacional han derivado en la tendencia al predominio económico y político de los municipios del oriente del Corredor Costero, esto es, el Soconusco, y de manera destacada el municipio de Tapachula. ${ }^{14}$ A fines del siglo XIX, el Soconusco era más visible que la Costa, debido principalmente al dinamismo económico por la plantación de café, el sistema social de fincas y las relaciones sociales productivas que incluían la servidumbre por deudas (Renard, 2002; Benjamin, 1990). Estos procesos condujeron a una polarización regional: el área oriental ha concentrado la tecnología agrícola más avanzada, la infraestructura, equipo técnico y humano, así como la presencia de las instituciones de desarrollo del Estado. ${ }^{15}$ A su vez, el crecimiento económico regional, centrado en la producción agrícola, ha dejado de lado el ordenamiento territorial y la conservación de los recursos naturales.

Dos procesos han contribuido en la conformación histórica del Soconusco: la agricultura de exportación y la dinámica poblacional fronteriza. La última década del siglo XIX y la primera del XX marca en Chiapas y en el Soconusco una época de auge económico, centrada en el cultivo del café. Empresarios alemanes que venían desarrollando plantaciones del grano en el vecino país de Guatemala arribaron al Soconusco atraídos por las facilidades otorgadas por el gobierno mexicano bajo el régimen de Porfirio Díaz, entre ellas la definición de los límites internacionales en el año 1882. Además, estos actores enfrentaban en Guatemala una escasez y alto costo de las tierras. Junto con los empresarios, llegaron jornaleros agrícolas que les siguieron para trabajar en las mismas fincas. ${ }^{16}$ Esta fuerza de trabajo estuvo, desde sus orígenes, constituida por indígenas mames y después, por ladinos. ${ }^{17}$ Más tarde, estos peones de campo que al mismo tiempo, se establecerían en forma acasillada se constituyeron en núcleos de atracción de amigos y familiares de origen guatemalteco. El área productora fue establecida en las partes medias y altas del Soconusco, entre los 500 y 1,500 metros sobre el nivel del mar (De Vos, 2002; Renard, 2002; Martínez, 1993: 73; Lucero, et. al., 1994: 238).

Esta actividad agrícola de carácter comercial - aunque de una gran heterogeneidad en las lógicas de los actores, sistemas de producción y estrategias de sobrevivencia - ha sido grandemente extractiva y ha degradado el ambiente. La explotación y uso del suelo para fines agrícolas, ganaderos y forestales se ha cimentado sobre las tierras mejor dotadas de la región. Al cabo de décadas de explotación intensiva, la planicie costera prácticamente quedó deforestada (Lucero, et. al., 1994: 217). Sus ríos acusan ya en los años ochenta, cuando el algodón entró en crisis ecológica y económica, una severa contaminación, agravada con el arrastre de materiales sólidos provenientes de la actividad gana- 
dera y cafetalera principalmente, y por la presencia de fenómenos meteorológicos como el huracán Stan en el 2005 (Tovilla, 2005). Por otro lado, la comercialización de productos facilitaba el logro de excedentes monetarios que se fueron acumulando en pequeños grupos locales, sobre todo extranjeros. Así pues, esta forma de desarrollo económico regional derivó en una marcada desigualdad social. A lo largo del Corredor Costero predominan localidades rurales pequeñas y dispersas en las que las viviendas se han construido con palma y carrizo, y carecen de servicios básicos como agua y drenaje (Fletes, 2008; Lucero, et. al., 1994: 221, 226, 247).

\section{El poder y la construcción política de la región}

La dinámica económica regional no respondió sólo a un Geist capitalista y a las condiciones de los mercados agrícolas mundiales. Contribuyeron en ella instituciones locales como la servidumbre por deudas y la represión directa mediante la que se contrataba jornaleros indígenas de los Altos de Chiapas y de Guatemala. Tales instituciones fueron defendidas por los propios terratenientes, la famosa "familia chiapaneca", frente a la presión liberal de las fuerzas revolucionarias carrancistas durante las primeras décadas del siglo XX. En los años ochenta del siglo pasado las fincas aún recurrían a formas de trabajos similares a las mencionadas (Benjamín, 1990), y a la fecha se pueden encontrar trabajadores que desarrollan actividades para la misma finca donde lo hicieron sus padres y abuelos.

En segundo lugar, tal dinamismo se dio en un contexto de consolidación - disputada - de un Estado nacional bajo el régimen de Porfirio Díaz (Benjamín, 1990). La auténtica época de plantación, dice Báez, como actividad dominante en la región, "es resultado de un vasto proyecto del capital extranjero y sus socios locales en México que impulsa la colonización e inversión foráneas desde las mismas administraciones de los presidentes mexicanos Juárez, González y Díaz, interesados en desarrollar al país a partir de crear una infraestructura de cobertura nacional e internacional de transportes y las comunicaciones" (1985: 154). Actores gubernamentales influirían directamente en este proyecto, al imaginar la región como agroexportadora de café, y desarrollar las acciones necesarias para que ello se lograra. Un caso ejemplar es el de Matías Romero, funcionario tanto con Juárez como en el gobierno de Porfirio Díaz. Este actor promovió en 1875 la reglamentación de las propiedades y la legalización de derechos y garantías de los propietarios. Con estas gestiones, el Estado mexicano ganó la mayoría del Soconusco al establecer el Tratado de Límites con Guatemala (Peña, 1998: 24, 50). Posteriormente al tratado de límites, Romero empujó hacia la modernización del Soconusco, mediante propuestas para habilitar un puerto, construir carreteras y redes ferroviarias que lo unieran a México. Se propuso con ello llamar la atención de los hombres de negocios para que invirtieran en la región (Tovar, 2004). A la vez, Romero era propietario de tierras en la región, en donde producía ganado, café y hule. Impulsó sus negocios "utilizando su influencia como funcionario y representante de los intereses en México de millonarios extranjeros" (Báez, 1985: 156).

Asimismo, el Estado desarrollaría en las décadas subsiguientes la infraestructura necesaria para facilitar la comunicación del Soconusco con el exterior. En 1907 se construyó la vía del Ferrocarril Panamericano. ${ }^{18}$ Esta vía de comunicación y transporte de mercancías sustituyó a la del Puerto San Benito (en Tapachula), que era costoso, tardado y peligroso, y el de Puerto Arista (en Tonalá), así como el movimiento comercial fluvial a través de canoas a lo largo del Corredor Costero (Bassols, et. al. 1974: 31, 33, 67).

A mediados del siglo XX, tanto agentes privados como del Estado impulsarían la agricultura de exportación. En 1954, se construyó en el Soconusco el Distrito de Riego de Suchiate. ${ }^{19}$ Es paradójico que, aunque ubicados en la Región Hidrológica 23, la de mayor precipitación en el país, los agricultores y la agricultura del Corredor Costero (incluyendo al Soconusco) tienen un uso li- 
mitado de agua para riego. En el distrito de desarrollo rural (DDR ${ }^{20}$ de Tapachula, en el año 2005 se sembraron 356,059 hectáreas, y de éstas se regaron 22,798, incluyendo riegos a través de pozos profundos y estaciones de bombeo (García, 2005: 118,133; SIAP, 2007). La mayor superficie relativa de riego se ha concentrado en cultivos frutales (plátano), casi exclusivamente en los municipios de Mazatán y Suchiate, los territorios con una superficie plana más amplia.

El interés de los grupos del Estado en el Soconusco ha sido tal que en algunos periodos de gran conflictividad e incluso de guerra interna en Chiapas, el territorio fue considerado un área que había que proteger. Durante los años de la Revolución Mexicana, "los carrancistas estaban dispuestos a defender la salida del café, y los extranjeros plantadores solamente los observaban" (García de León, 1985: 263). Durante toda la guerra, los primeros garantizaron la tranquilidad en las fincas cafetaleras, "al parecer sellada en un pacto personal de Carranza con los alemanes [cafetaleros]" (García de León, 1985: 263). ${ }^{21}$

El proceso de la reforma agraria en Chiapas es otro espacio que ayuda a vislumbrar el diseño político y simbólico de la región. La oligarquía terrateniente ha obstaculizado la reforma. El proceso de contrarrevolución en Chiapas defendió los intereses de los grandes latifundistas enraizados desde la época del porfiriato, los cuales, en 1910, acaparaban 95\% de las tierras aprovechables del estado. Al final del periodo presidencial del general Cárdenas, en el estado sólo nueve predios de más de 40 mil hectáreas concentraban 19\% de la superficie total. Fue hasta 1940 cuando comenzó a repartirse tierras de grandes extensiones, en terrenos nacionales de la selva. El objetivo de colonizar esa área fue mantener las estructuras de poder agrarias en el estado. Las propiedades existentes no se verían afectadas. Con esto se fomentaba la protección de territorios que desde siempre habían quedado fuera de una posible expropiación. De esta manera existieron territorios y regiones, como el Soconusco, Istmo-Costa y Frailesca, donde el reparto agrario prácticamente fue nulo. En cambio, en las regiones Selva y Fronteriza (ambas zonas selváticas), en conjunto se llevó a cabo 50\% del reparto de tierras en la entidad (Núñez, 2005: 409-412). Por tal razón el proceso de reparto agrario no ha concluido, y en ello contribuyó la reforma del año 1992 al Artículo 27 Constitucional, en la que el discurso oficial afirmaba: "no hoy más tierras que repartir".

Muchos agricultores asientan que en el Soconusco nunca hubo apoyo "del gobierno", que los caminos e infraestructura en general siempre la hicieron los cafetaleros y demás empresarios locales (notas de campo). Relacionado con esta situación, una especificidad de este territorio son las demandas de autonomía respecto a Chiapas, por ser, dicen, un territorio autosuficiente, que aporta grandes recursos económicos y al que no se le recompensa con presupuesto gubernamental suficiente. Estas expresiones son históricas (Peña, 1998: 66; Guillén, 1998); se han presentado en manifestaciones en la ciudad de Tapachula en la década de los noventa (Marina, 2002); y recientemente se dieron cuando actores políticos de Tapachula manifestaron su inconformidad con los resultados de la elección para gobernador en el año 2006, en la que el candidato "de la Costa" (apelativo que confirma la flexibilidad discursiva de la región) resultó perdedor. Como parte de su protesta, pedían la separación del Soconusco, de Chiapas (ElOrbe, 26 de agosto de 2006, Tapachula).

Así pues, el conjunto de discursos, relaciones y representaciones de la región deja ver que el dinamismo económico y la vocación agroexportadora no han sido favorecidas sólo por las condiciones naturales y geográficas, sino también por los proyectos y acciones de grupos de poder más cercanos social y políticamente con las elites gubernamentales, o que incluso forman parte de ellas. El resultado de esta dinámica es la exclusión de una diversidad de sistemas productivos que han acompañado históricamente a la agricultura comercial, y que también han sido sustento de la misma. Entre ellos se encuentran las siembras de maíz, hortalizas diversas, 
cacao y café en pequeña escala, desarrolladas por grupos de campesinos y jornaleros.

Al concebir territorios delimitados física y administrativamente, investigadores y agentes del Estado participan en la construcción de geografía. Mientras que históricamente las poblaciones del Corredor Costero han mantenido relaciones sociales estrechas, la literatura sobre la configuración de una "región agroexportadora" ha soslayado tal serie de interrelaciones tanto en los sistemas agrícolas, como en las dinámicas poblacionales y en las cuestiones políticas. La Costa (o Istmo-Costa) se ha configurado a partir de relaciones comerciales, productivas, familiares y sociales con Guatemala, y con el mismo territorio del Soconusco. Incluso, ciudades como Arriaga y Tonalá fueron a principios de siglo XX, económicamente importantes en relación con Tapachula que ahora guarda una centralidad en las dinámicas regionales (Bassols, et. al., 1974). La delimitación e importancia del Soconusco no sólo es económica y productiva, sino también política y simbólica, tanto para los actores "locales" como para los "externos", funcionarios, empresarios y emigrantes.

\section{Las políticas económicas neoliberales y sus efectos en la agricultura regional}

En el año 2005, el DDR Tapachula ocupó el tercer lugar en el valor de la producción agrícola en relación con los demás DDR del país. Sin embargo, el Corredor Costero presenta algunos municipios y localidades con alta marginación, que es creciente en el caso de Tonalá (PNUD, 2005; CONAPO, 2005; y notas de campo). Un aspecto en la explicación de esta contradicción, además de la estructura agraria y social edificada a través de la historia, se refiere al cambio y sesgos del modelo de desarrollo económico. A partir de la década de los ochenta, en México se realizaron cambios radicales en las políticas económicas, que implicaron una transformación de la intervención del Estado en los aspectos sociales (salud, educación, financiamiento) y económicos (comercio do- méstico e internacional), así como el desmantelamiento y privatización de las empresas paraestatales del sector agrícola (Zapata, 2005).

No puede establecerse una relación directa entre políticas y la transformación regional. Estos efectos no son lineales, sino mediados por las instituciones, actores sociales y la historia local. Pero es posible inferir cambios regionales asociados con el nuevo contexto político económico. De hecho, ya en los años setentas y ochentas, Chiapas atraía mayor atención nacional e internacional puesto que "contaba" con una reserva de recursos estratégicos para el país:

Un espacio de frontera en donde se encuentran importantes yacimientos de petróleo, gas y aceite, y se ubican las más extensas reservas de bosques y selvas tropicales del país, así como corrientes de agua para la generación de energía hidroeléctrica (Villafuerte, 2001; Aubry, 2005).

Por otro lado, se vio a Chiapas como un espacio de seguridad nacional, pues en los ochenta se había presentado una guerrilla en Guatemala que había expulsado población hacia los estados de la frontera sur mexicana (Villafuerte y García, 2006). Guillén (2003) plantea la importante hipótesis de que durante estos años se han reducido los espacios de acción de los grupos de poder estatal respecto al federal. De este reacomodo han salido mejor librados aquellos grupos que han establecido alianzas con los gobiernos triunfantes.

Estos acomodos político sociales, el nuevo modelo de intervención estatal en la agricultura, y la heterogeneidad económica y sociocultural de los agricultores, influyeron en una diversidad de resultados de las políticas en la región. A fines de los setentas desapareció el algodón, en medio de una severa afectación a los ecosistemas locales, lo que repercutió en el desempleo de jornaleros centroamericanos y de aquellos provenientes de la región vecina de Juchitán, del estado de Oaxaca. El plátano tuvo un importante crecimiento 
en la década de los ochenta, pero decayó a mediados de los noventa por la obsoleta infraestructura portuaria para comercialización internacional, una débil organización productiva y una reestructuración de la industria global de la fruta (Fletes, 2004). En estos años se ha reducido la superficie cultivada de granos como soya y maíz (Figura 2). Esta caída, en particular, obedece a la transformación del sistema estatal de apoyo a la producción y comercialización de granos, pues se retiró el amplio programa de subsidios, regulación de de precios, asistencia técnica y venta de insumos agrícolas. Por un lado, los subsidios se aplicaban también en la reducción de las tasas de interés de los créditos estatales. Por otro lado, la desaparición de CONASUPO dejó en manos de agentes privados el control de la comercialización de estos granos.

Las estrategias de los agricultores para enfrentar estos procesos han sido también diversas. En algunas superficies destinadas anteriormente a la producción de café, se ha establecido una serie de actividades que incluyen el cultivo de flor, plantaciones forestales, acuicultura o paseos turísticos. En otras áreas, las siembras del aromático están abandonadas o se encuentran en un proceso de transformación hacia agricultura orgánica. Como se ve en la Figura 2, la superficie destinada al café se ha mantenido estable. Pero los rendimientos se han reducido, lo que indica menor atención al cultivo. También se han establecido siembras de rambután, principalmente en las partes medias del "Soconusco". En la "Costa", por otro lado, la actividad ganadera sigue siendo importante, y se han establecido áreas de acuicultura. Lo que se observa en general es una mayor diversificación de las actividades de sustento. Por ejemplo, se ha incrementado la emigración de la población del Corredor Costero a los Estados Unidos (Jáuregui y Ávila, 2007).

En ese sentido, la valorización del territorio ha sufrido transformaciones. En un caso, se puede mencionar la presencia del turismo en las partes altas del Soconusco, promovido en especial por los finqueros.
En contraste, en otras áreas el territorio es calificado por los agricultores como en permanente rezago y crisis. Allí se ubican en particular aquellos grupos de población que fueron dotados recientemente con tierra ejidal en áreas con severidad afectadas en su fertilidad por la compactación de tierras y las aplicaciones de agroquímicos para plantaciones. Otros grupos excluidos son aquellos que se encuentran en tránsito hacia el centro del país o a los Estados Unidos.

La reorientación de la agricultura en el Corredor Costero quizás se haya reflejado entonces, en alteraciones en los significados que los actores sociales tienen sobre la agricultura, y por lo tanto en sus prácticas de cultivo, más no en lo que pudiera entenderse como una crisis de vocación o en un deterioro del valor material y simbólico de la agricultura. Este hecho habla de una particularidad de esta región, que es la importancia de la agricultura (la cual se basa, en parte, en el clima caluroso la mayor parte del año, la alta precipitación pluvial y la humedad de los suelos) y los procesos con ella relacionados, económicos, políticos o culturales. Los actores locales están especializados en la agricultura, con experiencias históricas que se van transmitiendo de generación en generación, lo cual les ha permitido enfrentar diferentes situaciones problemáticas. Como ejemplos, existen casos de agricultores que acudieron por décadas a trabajar a alguna ciudad del centro de México, para regresar luego a hacerse cargo de tierras y cultivos, con lo cual han dado educación formal a sus hijos, algo que ellos no obtuvieron. O por otro lado, agricultores que bajo duras condiciones económicas y sociales en su niñez, y con base en un esfuerzo tenaz, efectúan hoy una agricultura de gran escala (notas de campo). Para estos agricultores el territorio se ha revalorizado, a pesar de la crisis agrícola relacionada con las políticas económicas. Estas diferentes respuestas expresan la heterogeneidad de las experiencias de los actores sociales, de sus lógicas de agricultura y de su percepción del espacio. 


\section{Reinvención de la vocación regional agroexportadora: la agroindustria de mango}

Entre los cambios socioproductivos recientes destaca el de la producción de mango, que se presenta como alternativa o, en numerosas ocasiones, como complemento, a la producción de café, plátano, soya y maíz. Los procesos socioculturales de la agroindustria de mango dan cuenta de que el Soconusco y la Costa no son ámbitos separados, sino están articulados y desarticulados de manera dinámica a través de procesos de poder económico, político y simbólico, los cuales influyen en la valorización, representación y construcción del espacio.

En los años sesenta, el INMECAFÉ (Instituto Mexicano del Café), había obtenido una nueva variedad de mango a partir de la reproducción de varetas de unos árboles localizados en un predio urbano en Tapachula. Este mango, que hoy algunos técnicos consideran representó un "rescate genético", puesto que la variedad "ya estaba ahí", fue denominado "ataulfo", haciendo referencia al nombre de la persona dueña de aquel predio. En esos años, se establecieron algunas huertas del mango. Pero fue en los años ochentas cuando la superficie sembrada comenzó a crecer. El mango empezó a "intercalarse" en áreas de maíz y soya. Hoy hay más de 25,000 hectáreas sembradas, y las exportaciones han crecido más de diez veces respecto a los volúmenes de mediados de los noventas. ${ }^{22}$

En estas décadas puede observarse una nueva configuración temporal agroexportadora de la región, en la que las formas de intervención del Estado ya no son las mismas. Las instituciones de financiamiento, comercialización, seguros, insumos agrícolas, organización de productores ("sociedades ejidales"), y transformación industrial, ya no existen. En su lugar aparecen agentes privados como las empresas empacadoras, $y$, relacionado con ello, grupos de grandes agricultores que influyen en la organización de la agroindustria. Ellos, en alianza con agentes del Estado, establecerían las reglas de producción y comercialización de la fruta, teniendo como eje ordenador la regulación de sanidad. Esta nueva configuración sociotécnica que respondía a la necesidad de una "inserción exitosa en el mercado", 0 competitividad, conllevó procesos de identidad y diferenciación territorial. En el contexto de minifundismo de la producción de mango ( $80 \%$ de los productores con menos de 5 has.), a la par de una concentración de la tierra, uno de los resultados de este reordenamiento social ha sido una desigualdad en las formas en que participan los diferentes actores productivos y comerciales en la organización, y en la distribución de las utilidades, de la agroindustria (Fletes, 2007; 2008).

Un espacio donde se han manifestado estos procesos de diferenciación socio-territorial corresponde al establecimiento de una "Denominación de Origen Mango Ataulfo del Soconusco, Chiapas" (DO). Inicialmente, se propuso esta distinción para el estado de Chiapas en general. Después, los grupos de agricultores del Soconusco pudieron cambiar el nombre y acotarlo a "su región". Quedaron fuera de esta demarcación algunos pocos municipios del centro del estado productores de este mango. Pero también se excluyó a productores del Corredor Costero de los municipios Mapastepec, Pijijiapan, Tonalá y Arriaga. El argumento fue que estos municipios, entendidos localmente como pertenecientes a la región Costa, no producían el "mango ataulfo", sino otros mangos de menor calidad y atractivo comercial. En trabajo de campo, encontré que esas otras variedades locales, tal como la llamada "manililla", habían sido reconocidas por los comerciantes nacionales y habían "ingresado al mercado" antes que el ataulfo. Por otro lado, las estadísticas oficiales sobre las superficies sembradas de esos otros mangos no concuerdan con, de hecho reducen, las reconocidas por los productores locales que las desarrollan. Esto indica que la importancia de esas otras variedades ha sido reducida oficialmente. ${ }^{23}$

Otro argumento para la delimitación de la DO fue que en estos municipios había fuertes vientos que derribaban los árboles de mango. Un agricultor de Tapachula dijo: "del panteón de Huixtla para acá no hay vientos", 
y que esa era la zona "más productiva de toda la costa". Aquí aparecen elementos de distinción geográfica y social que se habían construido desde la misma academia: "Mapastepec no pertenece al Soconusco", habían dicho algunos de estos académicos, y lo enfatizaron los productores. Así pues, la forma en que se patrimonializa el espacio a través de la definición de una zona de DO, a la cual tenían derecho sólo los productores comerciales y orientados a la exportación, refleja una representación simbólica del territorio como agroexportador, delimitado y exclusivo.

Existen otros procesos que objetivan lo simbólico agroexportador, definen la región y reproducen esta diferenciación social. Presento aquí el caso del programa de sanidad, actualmente el único mediante el cual el Estado canaliza recursos a los productores de mango organizados en Juntas Locales de Sanidad (Fletes y Ocampo, 2006). De un modo histórico, los proyectos de actores empresariales y del Estado facilitaron en la región Soconusco una elevada producción agrícola y la canalización de alguna fracción de esta producción al mercado externo. Estos procesos le concedieron un reconocimiento como región agroexportadora. Sin embargo, junto con los procesos de corte mercantil y económico se constituyó una extensa red de relaciones sociales entre agricultores "locales" y agentes del Estado, que permite la comunicación permanente y directa entre ellos. Un ejemplo de ello se muestra en la formación a principios de los años noventa de un Comité Regional de Sanidad Vegetal de la Frontera Sur, cuya presidencia fue asignada de manera directa por funcionarios federales a un anterior dirigente de una asociación de productores de algodón (notas de campo). En este caso, los agentes del Estado reconocían capacidad y liderazgo regional en este tipo de agricultor, pues tenía cierta experiencia en la sanidad vegetal. Tal asignación directa excluía de manera automática la incorporación de un numeroso grupo de agricultores de "subsistencia" en el Corredor Costero, ya que no habían participado en la producción de al- godón y no pertenecían a la red de relaciones sociales del nuevo presidente.

La formación de este Comité, permitía además la renovación de alianzas entre agricultores "empresariales" y el Estado, a la luz de la transformación que éste venía realizando en sus formas de intervención. En este momento, el lema de la intervención estatal se basaba en la "sanidad" para la competitividad agrícola, que se realizaría entre otros aspectos a través de una descentralización de las decisiones para el desarrollo de la agricultura, la canalización de recursos económicos por el gobierno estatal y productores, y, por último, mediante la participación activa de los productores en la organización de la sanidad. Sin embargo, el Comité mencionado y la oficina encargada de sanidad a nivel nacional fueron severamente cuestionados por productores del "sector social" de Chiapas y otras entidades durante los años noventa, debido a la centralidad y verticalidad que tales productores detectaban en la toma de decisiones y organización de la sanidad en ambos niveles. Por estas presiones sociales, y una reorientación de la política agrícola y de sanidad, estos organismos fueron reemplazados por un Comité Estatal de Sanidad Vegetal del Estado de Chiapas (CESAVECHIS) y Juntas Locales de Sanidad Vegetal, entre los años 2001 y 2002.24

La afirmación de un agricultor de Tapachula muestra la reproducción de condiciones de desigualdad y exclusión que se gestaba en este proceso de transformación del Estado: “aquí debe estar la coordinación de este programa [de sanidad, porque es la zona más productiva y aquí están los exportadores]: aquí está todo", dijo. Esta valorización del territorio y la agricultura se da también por los agentes oficiales, quienes reconocen sólo algunos grupos de productores cuando pretenden "transmitirles" información. La fuerza simbólica y poder de la tradición agroexportadora se refleja en la canalización de recursos sumamente superiores a las zonas reconocidas como exportadoras, en detrimento de las calificadas como de agricultura tradicional. El caso es evidente si se compara la asignación oficial de 
recursos a la sanidad de mango, respecto a la de cultivos básicos como café. En el año 2005, bajo el Programa de la Alianza, los gobiernos federal y estatal asignaron 9.8 millones de pesos al programa de sanidad relativo a la fruta, y 2.4 millones a la sanidad de café (Comunicación directa de personal CESAVECHIS; ver Fletes, 2008). De los recursos canalizados al mango, 35\% se asignó a una sola Junta Local de Sanidad — son siete Juntas a nivel estatal-, aquella donde se ubican las empresas de exportación y en donde sus actores defienden la vocación agroexportadora. Cabe resaltar por un lado, frente a esto, que las exportaciones de mango representan entre 10 y 15\% de la producción total y que se realizan por un grupo reducido de empresas (once, en la última temporada). La mayoría de ellas no son propiedad de grupos de agricultores locales, sino de comerciantes que han "venido" de las zonas de distribución mayorista a las zonas de producción y, por otro lado, se encuentran algunos empresarios locales que han pasado de otros negocios a la comercialización del mango. Los mismos empacadores de exportación consideran que el mercado internacional debe evaluarse de acuerdo a las circunstancias de precios, regulaciones y organización temporal específica de las cadenas agroindustriales (tipos de actores, condiciones naturales, políticas nacionales e internacionales), por lo que tal mercado no representa para ellos una meta automática como establece el discurso oficial de la competitividad, y como se enuncia en el discurso regional de agroexportación. En ese sentido, la vocación productiva y agroexportadora, histórica, frente a una transformación regional y del Estado, se reinventa en la industria del mango, a través de los términos de "productividad", "competitividad" y "agroexportación".

\section{Reflexiones finales}

La reinvención de una vocación agroexportadora regional expresa los aspectos simbólicos del Corredor Costero como espacio percibido, representado y usado de una manera flexible por los proyectos e imaginaciones de los grupos de actores sociales. El paulatino dominio económico regional establecido por algunos grupos de agricultores se relaciona con la constitución de una industria de café y otras plantaciones comerciales. Pero como sustento de ello se encuentran los intereses de actores políticos, no desligados de los primeros, que imaginaron y construyeron la región como proveedora de productos agrícolas para el mercado internacional. Funcionarios gubernamentales, además de agricultores y comerciantes de distinto origen, han considerado esta región no sólo como espacio de intervención para el desarrollo, sino también como una oportunidad de negocio (Báez, 1985; Fletes, 2008).

La concentración de la dinámica económica en el área oriental del Corredor Costero ha conducido a una polarización y grandes desigualdades regionales, tanto entre sus diferentes territorios como "dentro" de tales espacios. Contingentes de población han estado excluidos de la actividad agroexportadora, y de este espacio transnacional. La cualidad de productor y región agrícola "empresarial" y "exportadora" se convierte en símbolo de negociación entre los actores diversos en la región, tal que se presenta como un atributo para la obtención de los escasos recursos otorgados por el Estado neoliberal. Este símbolo, además, encaja perfectamente en el lema de la "necesidad de competitividad" en el contexto de la globalización económica. Se presenta así como un elemento que excluye a un sector amplio de actores agrícolas.

\section{Notas}

${ }^{1}$ Una versión preliminar de este trabajo se presentó como ponencia en el Primer Seminario del Proyecto El territorio y sus construcciones. Miradas cruzadas México-Francia (2004-2007). Agradezco la invitación que me hizo el Dr. Francisco Peña (COLSAN, México) para participar en ese proyecto, así como el apoyo de la Dra. Claudia Cirelli (Universidad de Tours, Francia). 
${ }^{2}$ La denominación Corredor Costero se realiza con fines analíticos, pero a su vez se basa en la literatura que ha estudiado desde una perspectiva histórica y geográfica esta región compleja. Ello se explica en el tercer apartado de este trabajo.

${ }^{3}$ Este análisis se basa en trabajo etnográfico realizado mediante estancias periódicas en la región durante 2006 2008, que abarcó observación participante, entrevistas en profundidad e historias de vida con productores, empacadores, funcionarios y líderes de organizaciones sociales, que dio lugar a mi Tesis de Doctorado (Fletes, 2008). Esta investigación de largo aliento nació a partir del interés que he tenido en el análisis de las transformaciones del campo mexicano a la luz de los cambios en las formas de participación del Estado, y de un dinamismo cada vez más intenso en las cadenas agroalimentarias globales. En particular, la investigación de Tesis de Doctorado nació de una experiencia de investigación previa sobre la "Coordinación territorial de las cadenas agroindustriales de mango en Colima” (año 2000), así como, posteriormente, del anuncio de la aprobación de una "Denominación de Origen Mango Ataulfo del Soconusco, Chiapas" en Tapachula en el año 2003. Mi interés por el anuncio de esta denominación se basaba tanto en que era la primera distinción geográfica concedida a una fruta en México, como en que evidenciaba -de manera preliminar- una situación productiva y organizativa distinta a la de Colima en donde la industria del mango se encontraba en crisis, después de haber sido durante los años noventa uno de los principales estados exportadores de la fruta.

${ }^{4}$ Cf. el trabajo de Fletes (2006), que analiza los cambios y aportes recientes en el estudio de región y el desarrollo regional.

${ }^{5}$ Para análisis detallados sobre la noción de región en antropología, ver los trabajos de Viqueira (2001) y De la Peña (1991).

${ }^{6}$ Existe una Asociación Mexicana de Ciencias para el Desarrollo Regional dirigida por el Instituto de Ciencias Económicas de la UNAM, que realiza un encuentro anual con la asistencia de cientos de socios, y en donde las conferencias magistrales tienen en general una perspectiva económica (AMECIDER, 2007).

7 Es conveniente destacar aquí el trabajo de Giménez (1996), quien ve la región como una de las escalas del territorio. El término región designa unidades territoriales que constituyen subconjuntos dentro del ámbito de un Estado. El territorio remite a cualquier extensión de la superficie terrestre habitada por grupos humanos y delimitada (o delimitable) en diferentes escalas. Se trata siempre de un espacio valorizado sea instrumentalmente (bajo el aspecto ecológico, económico o geopolítico), sea culturalmente (bajo el ángulo simbólico-expresivo).

${ }^{8}$ El término de Cuencas (hidrológicas) hoy es central en algunos programas de desarrollo regional, pero no en el sentido anterior, de construcción de infraestructura para modernización del país. En algunas secretarías de Estado, la Cuenca Hidrológica se ha convertido en el área de intervención y coordinación de actores para el desarrollo. Este término establece una referencia principal de una serie de participaciones de distintos actores. Los agentes de los municipios y de los gobiernos estatales (en especial, de las Secretarías de Desarrollo Rural), de algunas secretarías del gobierno federal y organismos descentralizados (Secretaría de Agricultura y Desarrollo Rural; Comisión Nacional del Agua), los técnicos profesionistas (como planificadores y diseñadores de proyectos), y los beneficiarios (agricultores y habitantes de pequeñas localidades rurales), son (o se espera sean) co-partícipes en la planeación y desarrollo territorial por Cuencas. Este programa ha encontrado no pocos obstáculos para la coordinación entre los actores locales beneficiarios, y de éstos con los agentes municipales. Los técnicos dicen que los habitantes de las diferentes localidades donde se aplican los programas no entienden o no conciben trabajar de manera coordinada y que "no pueden imaginar que están asentados" en una Cuenca. Mientras tanto, estos habitantes desarrollan, por supuesto, sus actividades de acuerdo a su experien-

Revista LiminaR. Estudios sociales y humanísticos, año 7, vol. VII, núm. 2, diciembre de 2009, Tuxtla Gutiérrez, Chiapas, México. ISSN: 1665-8027 177 
cia, relaciones y prácticas, por lo que ha resultado difícil que "colaboren" con los demás habitantes en las distintas áreas de la Cuenca. Los funcionarios municipales en ocasiones han usado los recursos asignados para el programa de Cuenca en otras actividades "más urgentes", y esto ha retrasado la operación del programa.

${ }^{9}$ Estos autores no comparten una perspectiva única respecto a la región o a las delimitaciones socioespaciales. Existen mayores similitudes entre las posiciones de Roberts, Anderson y Pujadas, porque resaltan los procesos socioculturales y de poder "productores" de región. Por ejemplo, al estudiar el nacionalismo y su difusión, Anderson (1996) da cuenta de cómo aristocracias coloniales, cuerpos militares de distintos rangos, entidades económicas, y Estados, han intentado, a través de estrategias que pueden identificarse en el "mapa", "el censo" y "el museo", configurar representaciones espaciales que suelen reducir y homogeneizar la compleja diversidad natural-social de los territorios, poblaciones y sistemas. La representación del espacio por grupos de actores hace visibles ciertos procesos pero esconde otros. Para este autor, los conflictos de intereses nacionales, los símbolos y los imaginarios de clases, así como sus interacciones con las "culturas locales", tienen un papel primordial en la formación de regiones (especialmente en la delimitación de las fronteras nacionales). Por su parte, Nay (1998) se centra en el papel que desempeña la acción de comunicación política en la estructuración y la regulación estratégica del poder territorial. En ese sentido, lo que este grupo de autores sí comparte es la idea del dinamismo de las configuraciones socioterritoriales, más que su definición exclusiva, estática y simplista a partir de indicadores oficiales y económicos.

${ }^{10}$ En la Figura 1, la agrupación de los municipios en regiones Costa y Soconusco corresponde a la división político administrativa oficial.

${ }^{11}$ Chiapas se integra a México en 1824. Un mes antes de la votación que decide la anexión, el Consejo Municipal Local en Tapachula anunció que el Soconusco se anexaría a las recientemente constituidas Provincias
Unidas de América Central. Para evitar la guerra, México y Guatemala acordaron que el Soconusco se gobernaría de manera independiente hasta que se lograra establecer un acuerdo fronterizo. Así lo hizo hasta 1842, cuando fue anexada militarmente a México y se unió a Chiapas (Benjamín, 1990: 42,44).

${ }^{12}$ La incursión de la Sierra Madre de Chiapas hacia el litoral, hasta escasos 12 kms. a la altura de Tonalá, establece una barrera natural a los vientos húmedos del norte (Toledo, 1994a: 58). La influencia de los fuertes vientos desecantes del noroeste, un régimen de lluvias que oscila entre los 1200 y $1600 \mathrm{~mm}$ anuales, y estaciones secas que se prolongan durante seis meses al año, crean en la planicie costera condiciones de baja humedad propicias para la proliferación de gramíneas y poco aptas para el desarrollo de una abundante cubierta vegetal o para el establecimiento de cultivos anuales.

${ }^{13}$ Estas cuencas se localizan, en orden de oriente a poniente, a lo largo del Corredor Costero representado en la Figura 1. La última, Ocuilapan-Mar Muerto, ocupa municipios limítrofes de Chiapas y el estado de Oaxaca.

${ }^{14}$ La actividad agrícola en el Corredor Costero ha tenido etapas bien definidas: en primer lugar destacó el cacao, cultivo de origen prehispánico y que actualmente conserva importancia económica por su producción y superficie sembrada. Sobre la costa y los declives bajos de la Sierra Madre de Chiapas, la ganadería empezó a tener auge desde los tiempos de la colonia. A principios del siglo XX predominaba todavía la agricultura de subsistencia. A la par que se abría paso a la ganadería se desforestaban las selvas. En las partes altas del Soconusco, con la desaparición de selvas y bosques, se dio paso a las fincas cafetaleras. Durante el periodo de la Revolución hubo una merma en el comercio del ganado. Floreció la plantación de hule; y después de cierto auge, declinó a mediados de la década de los cuarenta hasta casi desaparecer. Después del período del hule resurgieron las actividades madereras y las grandes fincas cafetaleras. Por 
los años cincuenta del siglo pasado, se introdujeron los cultivos de plátano y algodón en la llanura. El algodón declinó totalmente a finales de los setentas. En su lugar aparecieron extensas áreas maiceras y soyeras (Lucero, et. al. 1994: 217-219).

${ }^{15}$ Sin embargo, tanto visto en su interior, como en relación con los municipios de la Costa, este espacio guarda una gran diversidad en las formas y condiciones de vida de la población (Notas de campo).

${ }^{16}$ La emigración de población guatemalteca a México se relaciona también con el resurgimiento en Guatemala, a partir de 1876, del sistema colonial de trabajo forzado para el abastecimiento de mano de obra a los grandes predios privados de café, acompañado de leyes de vagancia (Martínez, 1993: 73).

${ }^{17}$ En el transcurso del porfiriato entraron al Soconusco inmigrantes franceses, italianos, griegos, belgas, suizos, ingleses, españoles y rusos (Tovar, 2004), además de población indígena de los Altos de Chiapas, quienes tenían en el Soconusco una alternativa al decaimiento cíclico de la actividad económica y agrícola de las tierras frías.

${ }^{18}$ Benjamín (1990), señala que esta obra tuvo un objetivo bélico, ante las pugnas con el vecino Guatemala, posteriores a la definición de los límites internacionales.

${ }^{19}$ Esta obra se enmarcó en la estrategia del gobierno federal señalada, de desarrollo regional a través de Comisiones de Cuenca Hidrográfica. Durante el periodo 1951-1986, la Comisión del Grijalva construyó cuatro grandes presas hidroeléctricas en Chiapas ("Malpaso", "La Angostura", "Chicoasén" y "Peñitas") que inundaron cien mil hectáreas de tierras fértiles. El almacenamiento del agua se ha utilizado para generar energía eléctrica y no para regar tierras agrícolas. Además, sin utilizar el agua de las presas, se construyeron cuatro distritos de riego: Río Blanco, Suchiate, Cuxtepeques, y San Gregorio (García, 2005).

${ }^{20}$ DDR es la denominación del área territorial administrativa de SAGARPA (Secretaría de Agricultura, Ganadería, Desarrollo Rural, Pesca y Alimentación). El DDR de Tapachula incluye 16 municipios, de manera coincidente con la regionalización de INEGI para el Soconusco.

${ }^{21}$ Peña (1998:55) agrega: "las tropas federales primero y los carrancistas después cuidaron, en especial, el tendido de la vía ferroviaria para impedir que se saboteara la economía de los grandes propietarios de la tierra en Tapachula y sus alrededores".

${ }^{22}$ Se pasó de 1,500 en esa década a 24,000 toneladas en el presente año, con un promedio reciente de 15,000 toneladas.

${ }^{23}$ Acerca de la producción de conocimiento y representaciones que hacen agentes del Estado sobre la naturaleza y lo social, se puede revisar el trabajo de Mathews (2004; 2008).

${ }^{24}$ Para una revisión más amplia de la complejidad y dinamismo de la organización sociotécnica de la sanidad y las cadenas agroindustriales de mango en el estado, cf. Fletes (2008).

\section{Bibliografía}

AMECIDER (2007), Memoria del 12ํㅡㄹ Encuentro Nacional sobre Desarrollo Regional en México, Tlaxcala, México: El Colegio de Tlaxcala, CIISDER UAT, IIEc UNAM.

Anderson, Benedict (1996 [1983]), Imagined Communities, USA: Verso.

Asuad, Normand E. (2007), "Requerimientos de un enfoque de planeación regional para el Plan Puebla Panamá", en Alejandro Álvarez y Gabriel Mendoza (Coords.) Integración económica. Impactos regionales, sectoriales y locales en el México del siglo XXI, México: UNAM, Universidad Veracruzana, Universidad de Sonora, Editorial ITACA.

Aubry, Andrés (2006), "Las tragedias del Soconusco. Retrospectiva y prospectiva histórica", en Contrahistorias. La otra mirada de Clío, Marzo- Agosto, pp. 93-108.

Aubry, Andrés (2005), Chiapas a contrapelo. Una agenda de trabajo para su historia en perspectiva sistémica, México: Editorial Contrahistorias; Centro de Estudios, Información y Documentación Immanuel Wallerstein. 
Báez, Mariano (1985), “Soconusco: Región, Plantaciones y Soberanía”, en Andrés Fábregas, La formación histórica de la frontera sur, México: CIESAS, Cuadernos de la Casa Chata.

Bassols, Ángel, Dinah Rodríguez,; et al (1974), La Costa de Chiapas. Un estudio económico regional. México: IIEc., UNAM.

Benjamín, Thomas (1990), El camino a Leviatán, México: CONACULTA.

Catalán, Felipe (1995), La crisis de la producción de algodón y la expansión de la soya en la región del Soconusco, Chiapas, 1970-1988, México: UNAM.

CONAPO (2005), Índices de marginación, 2005, México.

De la Peña, Guillermo (1986), "Poder local, poder regional: perspectivas socioantropológicas", en Jorge Padua y Alain Vanneph (coords.), Poder local, poder regional, México: El Colegio de México/CEMCA, pp. 27-56.

De la Peña, Guillermo (1991), "Los estudios regionales y la antropología social en México”, en Pérez Herrero, Pedro (Comp.), Región e historia en México, México: Instituto Mora/UAM, pp. 123-162.

De la Peña, Guillermo (1999), "Las regiones y la globalización: reflexiones desde la antropología mexicana”, en Estudios del Hombre, núm. 10, México: Universidad de Guadalajara, pp. 37-57.

De Vos, Jan (2002), "La frontera sur y sus fronteras: una visión histórica”, en Edith Kauffer, Identidades, Migraciones y Género en la Frontera Sur de México, México: ECOSUR, pp. 49-67.

Del Rey P., Luís (1998), "Las expulsiones y desplazamientos en las comunidades indígenas de Los $\mathrm{Al}$ tos de Chiapas: consecuencias no anticipadas de la modernización”, en América Latina Hoy, núm. 19, pp. 13-21.

Estrada, Margarita y Pascal Labazée (2007), "Introducción”, en Estrada Margarita y Labazée Pascal (Coords.) Globalización y localidad. Espacios, actores, movilidades e identidades. México: Publicaciones de la Casa Chata, IRD-CIESAS, pp. 21-42
Fletes, Héctor (2004), "Territorio y transformación en la cadena productiva de plátano en el Soconusco, Chiapas", en Carta Económica Regional, núm. 87, Enero-Marzo, México: Universidad de Guadalajara, pp. 31-40.

Fletes, Héctor (2006), "Cadenas, redes y actores de la agroindustria en el contexto de la globalización. El aporte de los enfoques contemporáneos del desarrollo regional", en ESPIRAL. Estudios sobre Estado y Sociedad. núm. 37, Septiembre-Diciembre, México: Universidad de Guadalajara, pp. 97-122.

Fletes, Héctor (2007), "Competitividad global y desigualdad local: organización de la agroindustria de mango en Chiapas", en Raúl Miranda Ocampo y Luz María Espinosa Cortés (Edits.), Chiapas: La Paz en la Guerra, México: UNAM (FESI), ECOSUR, Editorial COMUNA, pp. 211-236

Fletes, Héctor (2008), La construcción de cadenas agroindustriales de mango en Chiapas. Diversidad y contingencia en la globalización, Tesis de Doctorado, México: CIESAS Occidente.

Fletes, Héctor y Ocampo Guadalupe (2006), "Mercado y Actores Sociales en la Construcción de la Calidad Agroalimentaria. El Caso del Mango en el Soconusco, Chiapas", en Quehacer Científico en Chiapas, vol. 1, núm. 1, Segunda época. Enero-Junio, México: Universidad Autónoma de Chiapas, pp. 75-85.

Fuentes, Noé; Alejandro Díaz B.; Sárah E. MartínezPellégrini (2003), Crecimiento con Convergencia o Divergencia en las Regiones de México. Asimetría Centro-Periferia, México: El Colegio de la Frontera Norte, Plaza y Valdés Editores.

García, Antonino (2005), "La política hidráulica en Chiapas y Tabasco: 50 años perdidos para el desarrollo de la región y su gente", en Edith Kauffer (Edit.), El agua en la frontera México-Guatemala-Belice, México: ECOSUR-UNACH, pp. 117-143.

García de León, Antonio (1985), Resistencia y utopía. Memorial de agravios y crónica de revueltas y profecías acaecidas en la provincia de Chiapas durante los últimos quinientos años de su historia, México: Ediciones Era. 
Giménez, Gilberto (1996), "Territorio y Cultura”, en Es tudios sobre las Culturas Contemporáneas, Época II, vol. II, núm. 4, diciembre 1996, México: CUIS, Universidad de Colima, pp. 9-30.

Guillen, Diana (1998), Chiapas 1973-1993. Mediaciones, politica e institucionalidad, Instituto Mora, México.

Guillen, Diana (2003), "Redimensionamiento de una frontera largamente olvidada Chiapas 1973-1993", en Frontera Norte, vol. 15, núm. 30, julio-diciembre, México: EL COLEF, pp.121-149.

INEGI (1985), Anuario Estadístico del Estado de Chiapas Edición 1985, México.

INEGI (1990), Anuario Estadístico del Estado de Chiapas Edición 1990, México.

INEGI (1997), Anuario Estadístico del Estado de Chiapas Edición 1997, México.

INEGI (1998), Chiapas. Información Básica del Sector Agropecuario, 1998, México.

INEGI (2006a), II Conteo de población y vivienda 2005: tabulados básicos: Estados Unidos Mexicanos, Disco compacto, México.

INEGI (2006b), Anuario Estadístico del Estado de Chiapas Edición 2006, Tomo II, México.

Jáuregui, Alfredo y María de J. Ávila, (2007), “Estados Unidos, lugar de destino para los migrantes chiapanecos", en Migraciones Internacionales, vol. 4, núm. 1, Enero-Junio, México: EL COLEF, Disponible en http://www.colef.mx/migraciones internacionales/ index.asp.

Lucero, Ramón; Josefina Medina; Yolanda Cervantes (1994), "Los usos del suelo", en Riqueza y pobreza en la Costa de Chiapas y Oaxaca, México: Centro de Ecología y Desarrollo, A. C., pp.211-313.

Marina, Aura (2002), "Pensar la identidad en una ciudad fronteriza: Tapachula, Chiapas", en Edith Kauffer (Edit.), El agua en la frontera México-Guatemala-Belice, México: ECOSUR, UNACH, pp. 167-184.

Martínez, Germán (1993), "Migración y poblamiento guatemalteco en Chiapas", en Revista Mesoamérica 25, pp. $73-100$.
Mathews, Andrew S. (2004), Forestry Culture: Knowledge, Institutions and Power in Mexican Forestry 1926-2001, PhD. Dissertation. U.S.A.: Yale University.

Mathews, Andrew S. (2008), "State Making, Knowledge, and Ignorance: Translation and Concealment in Mexican Forestry Institutions", en American Anthropologist, vol. 110, Issue 4, pp. 484-494.

Méndez, Arturo; Luis Pavón; Rogelio Rendón (2007), “La región sur-sureste en el contexto del nuevo patrón de acumulación de capital", en Alejandro Álvarez y Gabriel Mendoza (Coords.) Integración económica. Impactos regionales, sectoriales y locales en el México del siglo XXI, México: UNAM, Universidad Veracruzana, Universidad de Sonora, Editorial ITACA, pp. 71-111.

Nay, Olivier (1998), "Construcciones simbólicas del territorio y estrategia de poder local", en Carlos Alba, Ilán Bizberg, Heléne Riviere (Comps.), Las Regiones ante la Globalización. Competitividad territorial y recomposición política, México: CEMCA, ORSTOM, COLMEX, pp. 47-69.

Núñez, Violeta (2005), "El proceso de reforma agraria en Chiapas. El caso de San Miguel Chiptic: una comunidad indígena en lucha", en Gabriela Kraemer B. y Martha J. Sánchez (Coords. de Tomo) Los actores sociales frente al desarrollo rural, Tomo 4: Derechos étnicos y territoriales de la población indígena y campesina en México, México: AMER, Editorial PRAXIS, pp. 405-428.

Peña, Francisco (1998), "Frontera, Pobreza y Migración en Chiapas", en Francisco Peña (Coord.) Tres Ensayos sobre Chiapas. Los Retos de la Modernización Neoliberal, México: Universidad Autónoma Chapingo, pp. 15102.

Pérez, María Isabel (1998), El impacto de las migraciones y expulsiones indígenas de Chiapas: San Pedro Chenalhó y San Andrés Sacamchéen de los Pobres (Larráinzar), México: UNACH.

PNUD (2005), Informe sobre desarrollo humano. México 2004. El reto del desarrollo local, México: Grupo Mundi Prensa.

Pohlenz, Juan (1985), "La conformación de la frontera entre México y Guatemala. El caso de Nueva Huixtán en 
la selva chiapaneca", en Andrés Fábregas, La formación histórica de la frontera sur, México: CIESAS, Cuadernos de la Casa Chata, pp. 23-130.

Pujadas, Joan J. (2003), "Biografía de una frontera. Procesos de globalización en dos enclaves pirenaicos: Andorra y Cerdaña”, en Carmen Bueno y Encarnación Aguilar (Coords.) Las expresiones locales de la globalización: México y España, México: CIESAS, Universidad Iberoamericana, Grupo Editorial Miguel Ángel Porrúa, pp. 453-485.

Renard, Marie (2002), "El café en la frontera sur: vocación y destino", en Jürgen P., Alfred (Edit.) México y la cafeticultura Chiapaneca - Reflexiones y alternativas para los productores, Germany: Shaker Verlag, pp. 15-26.

Reyes, María E. (1992), El reparto de tierras y la política agraria en Chiapas, 1914-1988, México: UNAM.

Rivera, Jesús (2007), "Hacia una economía política de la integración: la vinculación local-regional como expresión del nuevo espacio económico y la redefinición de la especialidad sistémica", en Alejandro Álvarez y Gabriel Mendoza (Coords.) Integración económica. Impactos regionales, sectoriales y locales en el México del siglo XXI, México: UNAM, Universidad Veracruzana, Universidad de Sonora, Editorial ITACA, pp. 113-134.

Roberts, Bryan (1992), "The Place of Regions in Mexico", en Van Young, E. (Ed.) Mexico's Regions. Comparative History and Development, Center for U.S.-Mexican Studies, UCSD, pp. 227-245.

Saraví, Gonzalo (2003), "Efectos locales de la globalización: estrategias empresariales y estructura social en un distrito industrial (El caso de San Mateo, México)", en Bueno, Carmen; Encarnación Aguilar (Coords.) Las expresiones locales de la globalización: México y
España. México: CIESAS- Universidad Iberoamericana-Miguel Ángel Porrúa, pp. 169-190.

SIAP (2007), http://www.siap.gob.mx/aagricola_siap/ icultivo/index.jsp.

Toledo, Jorge (1994a), "Las dimensiones sociales", en Riqueza y pobreza en la Costa de Chiapas y Oaxaca, México: Centro de Ecología y Desarrollo, A. C., pp. 41-67.

Toledo, Jorge (1994b), "Las dimensiones estructurales", en Riquezay pobrezaen la Costa de Chiapas y Oaxaca, México: Centro de Ecología y Desarrollo, A. C., pp. 17-40.

Tovar, Elena (2004), "La inmigración extranjera en el Soconusco", en José Sánchez y Ramón Jarquín (Edits.) La frontera sur. Reflexiones sobre el Soconusco, Chiapas y sus problemas ambientales, poblacionales y productivos, México: ECOSUR, COCYTECH, H. Ayuntamiento de Tapachula, pp. 71-81.

Tovilla, Cristian (2005), "Agonía y desaparición de los ríos y humedales en la costa de Chiapas", en ECOFRONTERAS, núm. 25, Abril 2005, México: ECOSUR, pP. 5-8.

Villafuerte, Daniel (2001), Integraciones comerciales en la frontera sur. Chiapas frente al Tratado de Libre Comercio MéxicoCentroamérica, México: PROIMMSE-UNAM.

Villafuerte, Daniel y María del C. García (2006), "Estado, economía y política en la frontera sur de México", en Alberto Aziz y Jorge Alonso (Coords.) El Estado mexicano: herencias y cambios. Tomo I: Globalización, poderes y seguridad nacional, México: Cámara de Diputados, CIESAS, Miguel Ángel Porrúa, pp. 353-388.

Viqueira, Carmen (2001), El enfoque regional en antropología, México: Universidad Iberoamericana.

Zapata, Francisco (2005), Tiempos neoliberales en México, México: EL COLEGIO DE MEXICO. 
Figura 1. El Corredor Costero de Chiapas ${ }^{10}$

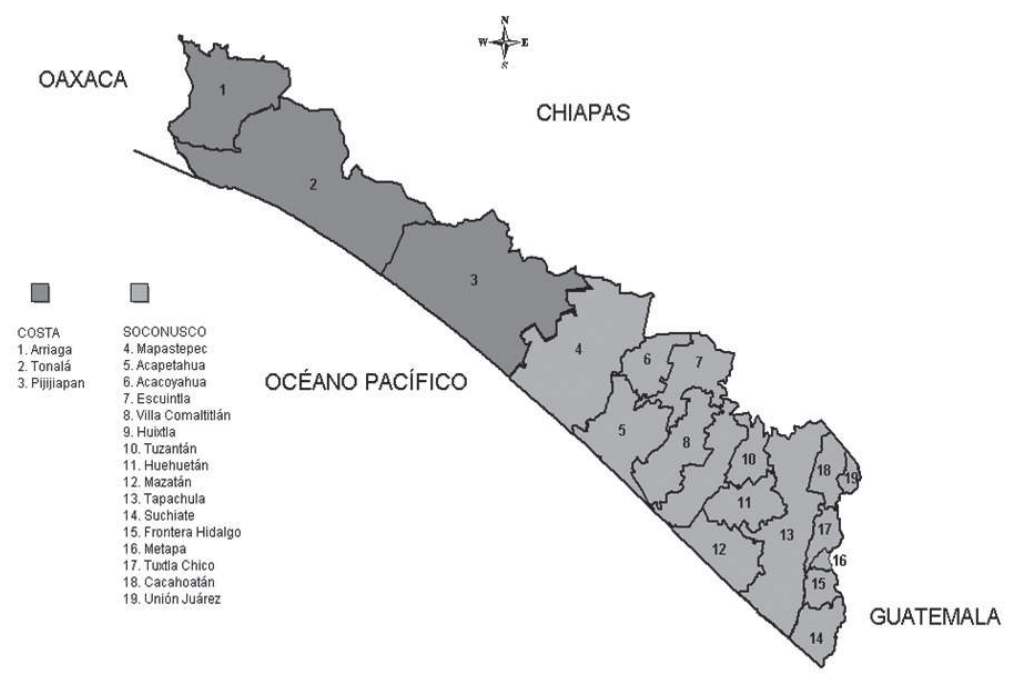

Fuente: Elaboración en Maplnfo, con información de INEGI.

Figura 2. Corredor Costero. Cambios en la superficie sembrada de los principales cultivos, 1970-2005 (has.)

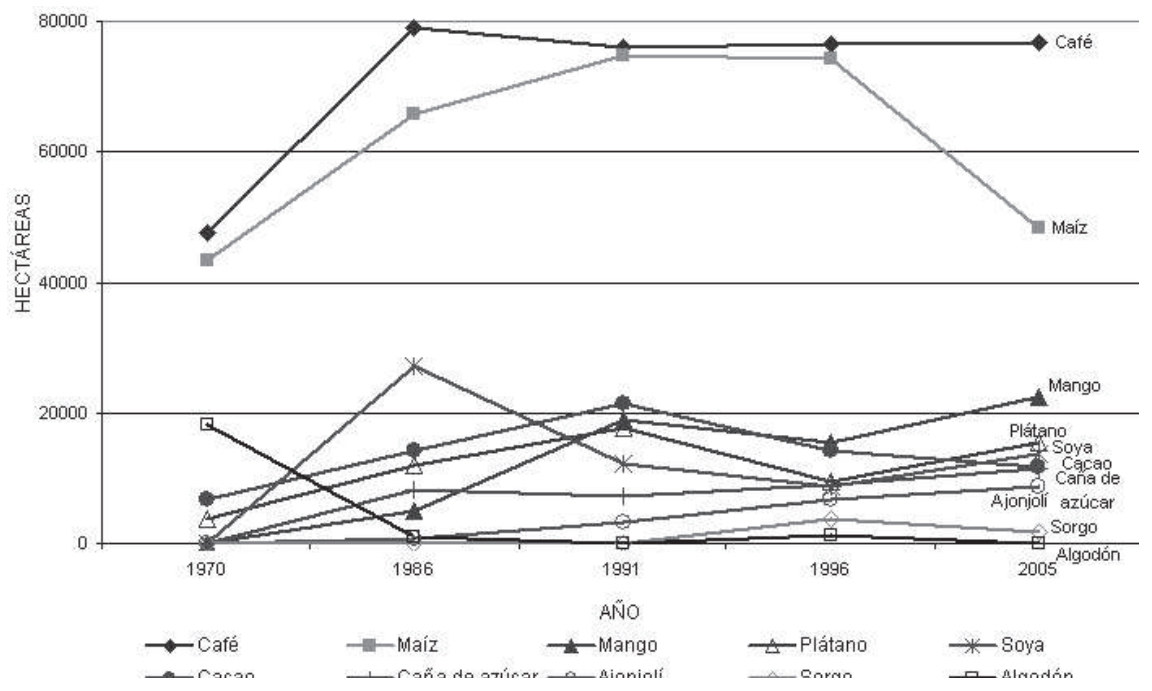

Fuente: INEGI, 1985, 1990, 1997, 1998, 2006b; Catalán, 1995 